HELMINTHOLOGIA, 55, 3: 195 - 203, 2018

\title{
Modulation of TLR2 and TLR4 in macrophages following Trichinella spiralis infection
}

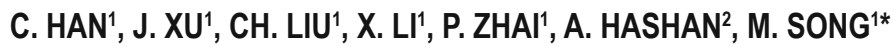

${ }^{1}$ College of Veterinary Medicine, Northeast Agricultural University, Harbin, Heilongjiang, 150030, PR China, *E-mail: songmx@neau.edu.cn; ${ }^{2}$ Tiemaike Animal Husbandry and Veterinary station, Fuyun, Xinjiang 836302, PR China

\section{Article info}

Received April 6, 2017

Accepted February 20, 2018

\begin{abstract}
Summary
Parasitic helminthes can suppress and/or regulate the host immune response to allow long-term survival and chronic infection where toll-like receptors (TLRs) expressed on macrophages play essential roles in response to parasitic infection. Semi-quantitative PCR and flow cytometry studies about the modulation of TLRs and cytokine profiles in macrophages following $T$. spiralis infection were performed. TLRs, MyD88 and NF-kB were up-regulated by T. spiralis infection and essential to the parasite life cycles. Cytokines profiles (IL-6, IL-10, IL-12, TNF-a) were modulated during $T$. spiralis infection. Results suggest that $T$. spiralis infection may regulate the expression of TLR4 on macrophages and TLR4/MyD88/NF-kB signaling pathways. This study provides further insights into the mechanisms of TLR-mediated post-inflammatory response during T. spiralis infection.
\end{abstract}

Keywords: Trichinella spiralis; Toll-like receptor; Helminth; Immune modulation

\section{Introduction}

Trichinellosis is a wide-spread foodborne zoonosis initiated by the ingestion of raw or poorly-cooked meats containing infectious Trichinella spiralis (T. spiralis) larvae. Trichinellosis is considered as a re-emerging disease and it has been reported worldwide. Trichinellosis is not only an important source of public health hazard but also an economic problem in animal production and food safety (Yang et al., 2010; Chen et al., 2012; Li et al., 2012; Yadav et al., 2012; Cui et al., 2013). Infection with T. spiralis represents a great challenge for the host immune response. It is due to parasite life cycle of the parasite which is accomplished in one host. The larvae are released from infective capsule-like cysts and undergo maturation process to reach the adult reproductive stage within the intestine. The newborn larvae released from the adult females disseminate through the host by the circulation. Larvae finally enter the skeletal muscles and develop into infective encysted muscle larvae that are essential for transmission (Kang et al., 2012; Riva et al., 2012). In order to complete the life cycle and survive in the host, $T$. spiralis influences the development of immune-regulatory mechanisms essential for immune tolerance (Radovic et al., 2015). However, the nature of the relationship between $T$. spiralis and the host organism, as well as mechanisms and signals that control the immune response, have been understood or investigated not sufficiently.

Helminthes have developed different evasion and suppression mechanisms what enable the establishment of infection with lowest possible damage to the host (Motran et al., 2017). The immune response caused by $T$. spiralis is characterized as mixed Th1/ Th2 type of immune response where during the intestinal phase, the Th1 response predominate and subsequently a Th2 response will follow (llic et al., 2012). Expulsion of the gastrointestinal adult is associated with a prominent mucosal mastocytosis mediated by a Th1 response involving the production of cytokines such as IL-4, IL-5 and IFN-y (Blum et al., 2013; Liu et al., 2013; Thrasher et al., 2013). The immunological response to $T$. spiralis muscle invasion

\footnotetext{
$\overline{* \text { - corresponding author }}$
} 
is primarily characterized by a Th2 phenotype, in which cells collected from cervical lymph nodes produce IL-5, IL-10, IL-13 and IFN-y after the stimulation with somatic larval antigens (Bruschi et al., 2011). IL-10 controls the level of inflammation induced by $T$. spiralis especially during the chronic phase of infection (Aranzamendi et al., 2013). Excretory-Secretory (ES) products from different stages of $T$. spiralis infection can modulate macrophages function in vitro by inhibiting pro-inflammatory cytokine production (Yu et al., 2013) and the muscle larvae ES products have the properties that regulate the immune response by its suppressive effect on dendritic cells (DCs) maturation (Aranzamendi et al., 2013; Gruden-Movsesijan et al., 2011). T. spiralis infection alters the immune response via increased production of both IL-4 and IL-10 and decreased production of IFN- $\gamma$ and IL-17 (Gruden-Movsesijan et al., 2010).

Pattern recognition receptors such as Toll-like receptors (TLRs) may regulate the response of DCs and macrophages, as well as the other immune cells of the innate immune system such as mast cells (Yu et al., 2013; Langelaar et al., 2009). In vitro, T. spiralis ES antigens can suppress DCs maturation but this effect depends on the type of lipopolysaccharide (LPS) used to activate these cells (Langelaar et al., 2009). Studies showed that the suppressive effect of ES on DCs maturation is restricted to TLR4 using different TLR agonists and the ES products can also interfere with the expression of several genes related to the TLR-mediated signal transduction pathways (Aranzamendi et al., 2012). Induction of inflammatory cytokines by LPS is mediated by nuclear factor-kB (NF-kB). The ES products may modulate the macrophages activities in vitro and the roles of ES products in the LPS-induced nuclear translocation of NF-KB are being investigated. Regulation of inflammatory cytokine induction via the NF-kB pathways is an important mechanism in parasite infection (Bai et al., 2012). Despite many immunomodulatory investigations concerning helminthes or their products, very little is known about the TLRs mechanisms and signals that control the immune response and systemic cytokine response in vivo. In this study, cytokine profiles in serum and macrophages were examined from mice infected with $T$. spiralis. The expression of TLR4 was determined by flow cytometry analysis and macrophages were analysed with semi-quantitative PCR during $T$. spiralis infection. In addition, the expression of MyD88 (myeloid differentiation primary-response gene 88) and NF-kB was measured by Western blot analysis. The different stages of $T$. spiralis had different impacts on the expression of TLRs and related signaling molecules.

\section{Materials and Methods}

\section{Animal and parasite infection}

Male BALB/C mice, 6 - 8 weeks old, purchased from the Experimental Animal Center of Harbin Veterinary Research Institute of Chinese, Academy of Agricultural Sciences (CAAS) were infected orally with 500 T. spiralis larvae (isolate code: ISS3; original host: domestic pig of Poland). The muscle larvae were isolated as described previously (Mido et al., 2012). The blood serum was collected from the mouse eye socket at $0,4,7,14,21$ and 28 days post infection (p.i.). The group sizes consisted of three mice per group per each time points.

\section{Abdominal macrophages isolation}

Infected mice were sacrificed at 4, 7, 14, 21 and 28 days p. i. and the uninfected mice were used as control. The RPMI 1640 medium (Gibco, Grand Island, USA) was instilled into the mouse abdomen and cells were concentrated by spinning ( $3000 \mathrm{~g}, 10 \mathrm{~min}$ ) and by subsequent supernatant removal. Tris- $\mathrm{NH}_{4} \mathrm{CL}$ was added to lyze the red cells and macrophages were cultured in RPMI 1640 supplemented with $10 \%$ fetal calf serum (Sigma, Saint Louis, USA) on 24-well plates and maintained at $37{ }^{\circ} \mathrm{C}$ in $5 \% \mathrm{CO}_{2}$ for $2 \mathrm{hr}$. After the incubation, the non-adherent cells were removed by washing and adherent cells were re-supplemented again in RPMI 1640 with $5 \%$ FCS. Afterwards counted and checked for viability. Macrophages were then seeded into 24-well plates and allowed to adhere for another $24 \mathrm{hr}$. Then the cells were collected and flow cytometry analysis was performed. Two treatments were carried out on macrophages. Cells were either LPS untreated or treated with LPS for the first $12 \mathrm{~h}$ (final conc., $100 \mathrm{ng} / \mathrm{ml}$ ). The cells and cultured and supernatants were collected and stored at $-80^{\circ} \mathrm{C}$ until the ELISA was performed.

\section{Cytokine and NO level analyses}

The levels of IL-6, IL-10, IL-12, TNF-a and NO in serum and cultured supernatants were determined by cytokine ELISA kit (RD Systems, Minneapolis, USA) according to the manufacturer's instructions. The absorbance of the wells was read at $450 \mathrm{~nm}$ on microplate reader (BIO-RAD 680, Hercules, USA). Cytokine and NO concentrations in examined samples were calculated according standard curves generated with known concentrations of cytokines (BD Pharmingen, San Diego, USA). Results are expressed in picograms per mililiter $($ pg.ml-1).

\section{Semi-quantitative RT-PCR}

Total RNA was extracted, from the samples of macrophages at different day p. i., by TRIZOL RNA extraction kit (Invitrogen, Vienna, Austria) and according to the manufacturer's instructions. The RNA from each sample was reverse-transcribed to cDNA with Reverse Transcription System (Promega, Madison, USA). The PCR primers were designed by use of the Primer-BLAST tool at the NCBI website. The forward primer of the TLR4 was 5'-tcacctgatacttattgctgg-3' and the reverse primer was 5'-agttgccgtttcttgttct-3' (GenBank accession number NM_021297.2). A pair of primer for TLR2 (5'-ctgagaatgatgtgggcgt-3' and 5'-cttggtgttcattatcttgcg-3'; GenBank accession number AF165189) was developed. Levels of target genes were normalized to that of $\beta$-actin as a housekeeping gene (5'-ctgtccctgtatgcctctg-3' and 5'-atgtcacgcacgatttcc-3'; GenBank accession number NM_007393). Amplification of the 
fragments at 538 bp TLR4 and 426 bp TLR2 and 218 bp $\beta$-actin was carried out by PCR. The PCR reaction was conducted under the following conditions: an initial denaturation at $95^{\circ} \mathrm{C}$ for $5 \mathrm{~min}$, 30 cycles of denaturation at $95^{\circ} \mathrm{C}$ for $30 \mathrm{~s}$, annealing at $53.5^{\circ} \mathrm{C}$, $55{ }^{\circ} \mathrm{C}$ and $55^{\circ} \mathrm{C}$ for $30 \mathrm{~s}$ and elongation at $72{ }^{\circ} \mathrm{C}$ for $30 \mathrm{~s}$, and a final extension at $72{ }^{\circ} \mathrm{C}$ for $10 \mathrm{~min}$ (Mini Cycler@ Peltier Thermal cycler, MJ Research, Waltham, USA). The PCR products were analyzed by electrophoresis on $1 \%$ agarose gel and the density of the PCR gene mRNA was divided by that of the density $\beta$-actin to obtain a normalized value for target gene expression.

A

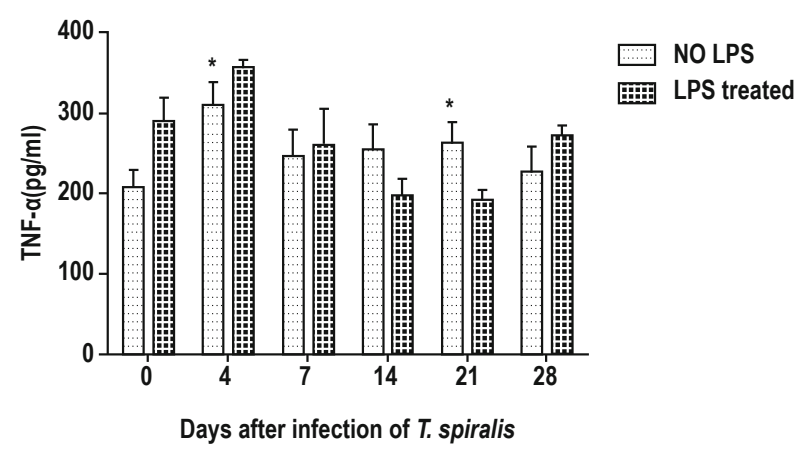

C

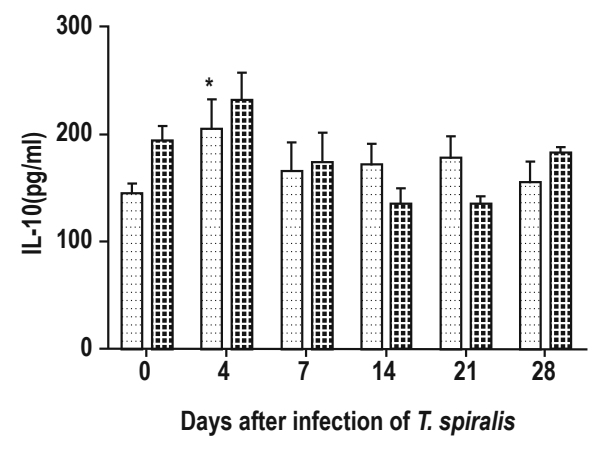

Flow cytometry

Abdominal macrophages were washed and re-suspended in PBS and cells were phenotyped for the expression of the CD282/TLR2 and CD284/TLR4 cell surface markers. $1 \times 10^{6}$ cells were incubated in the dark at room temperature for $1 \mathrm{hr}$ with PE-conjugated anti CD284 antibody (eBioscience, San Diego USA). Then the cells were washed twice with PBS and flow cytometry analysis was carried out on a FACScalibur (BD, San Jose, USA) equipped with FACS Diva 6.0 software.

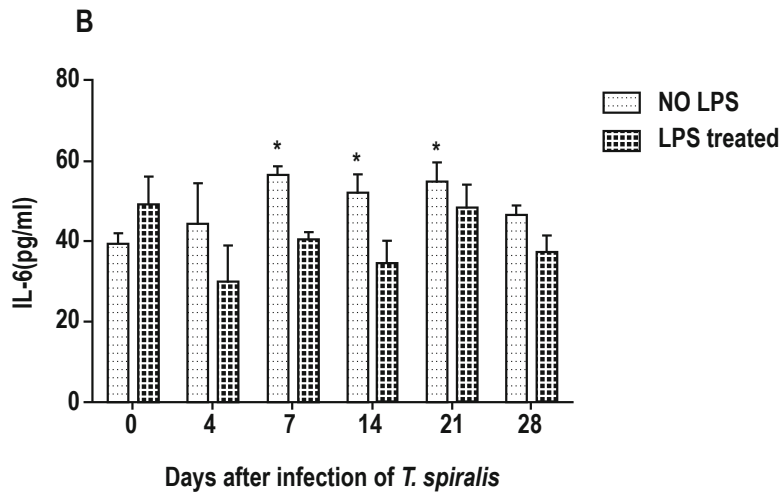

D

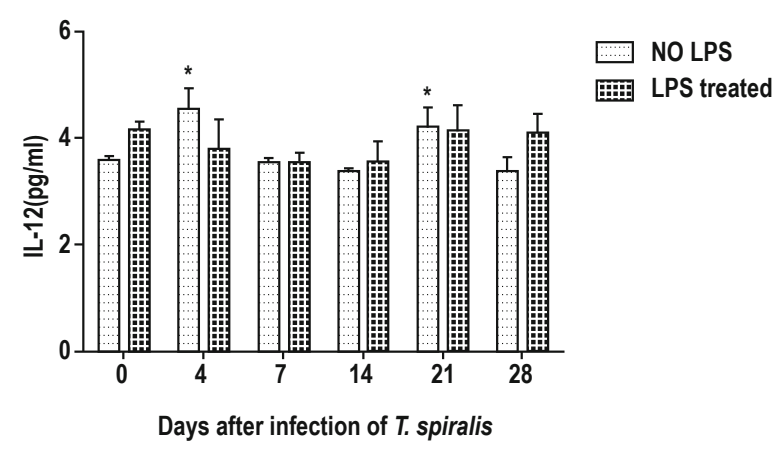

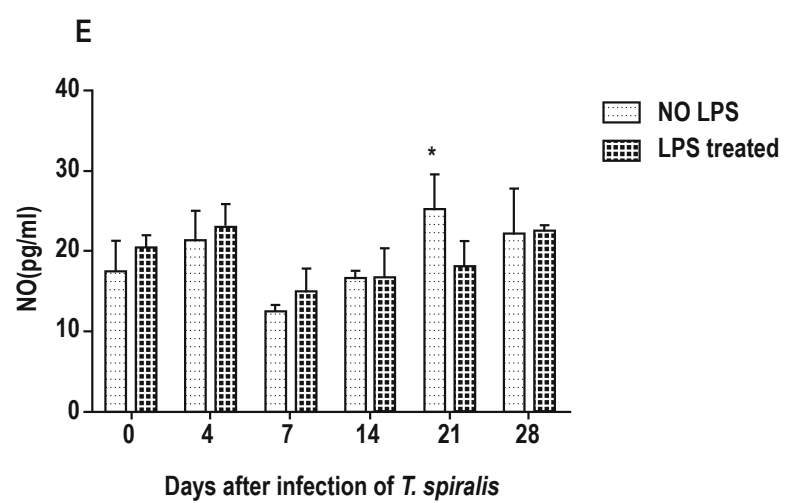

Fig. 1. Cytokine profile in the macrophages supernatants after infection with $T$. spiralis at the indicated time points. Cells were treated with or without LPS (final conc., $100 \mathrm{ng} / \mathrm{ml}$ ) for $12 \mathrm{~h}$. No cytokines production was detected in control group without T. spiralis infection (data not shown). A - E: TNF-a, IL-6, IL-10, IL-12 and NO levels in the cell supernatant were measured by ELISA. 
A

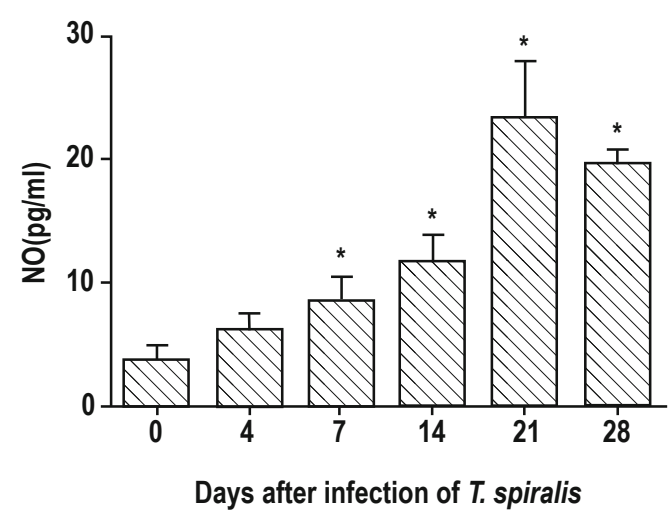

C

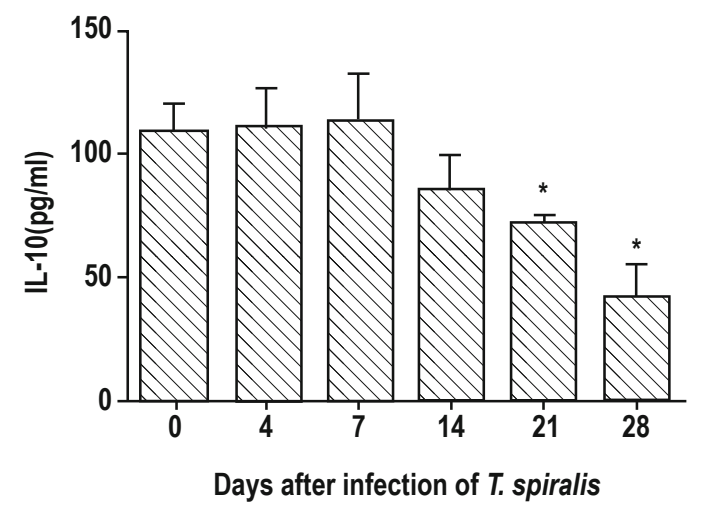

B

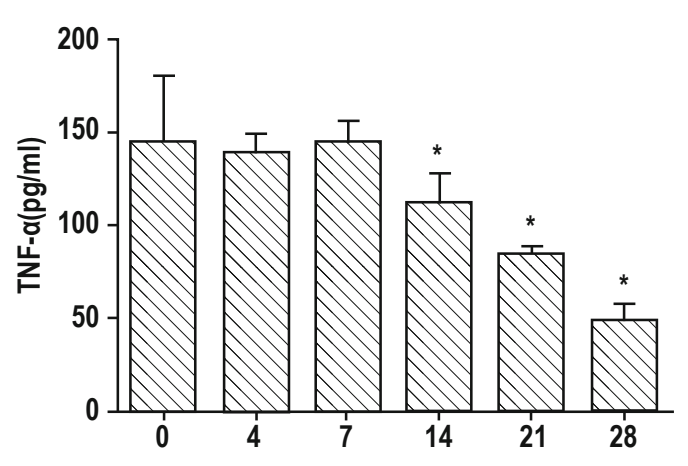

Days after infection of $T$. spiralis

D

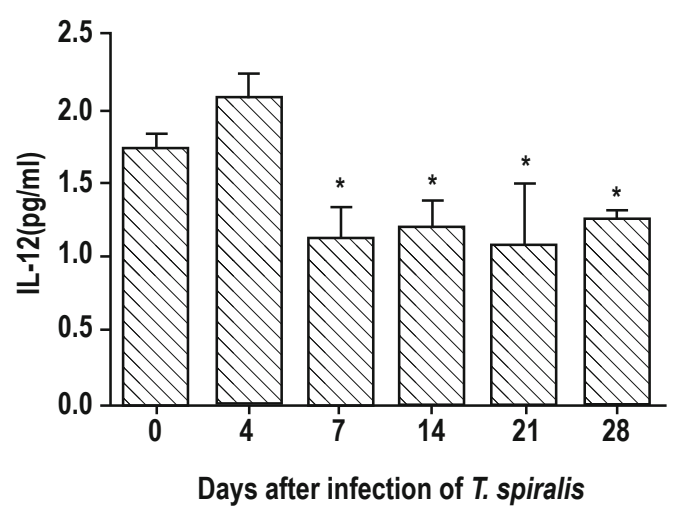

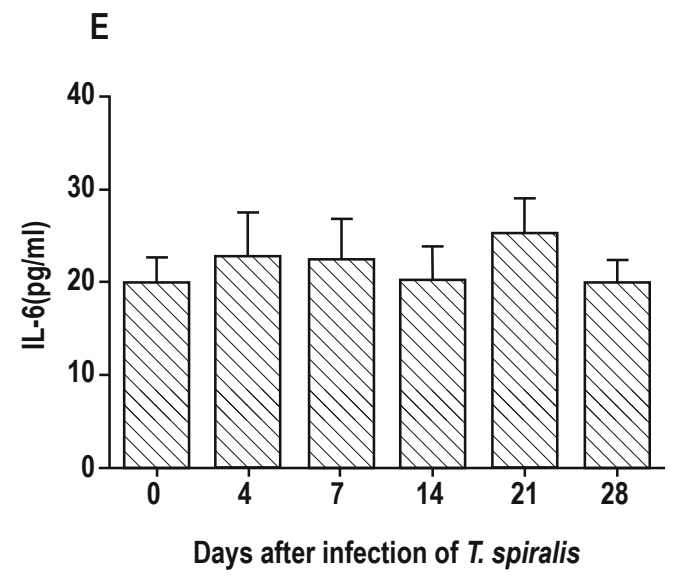

Fig. 2. Cytokine profile in the serum after infection with $T$. spiralis at the indicated time points. The serum was separated from blood taken from the mouse eye socket. No cytokines production was detected in control group without $T$. spiralis infection (data not shown). A-E: NO, TNF-a, IL-10, IL-12 and IL-6 levels in the serum were measured by ELISA. 
A

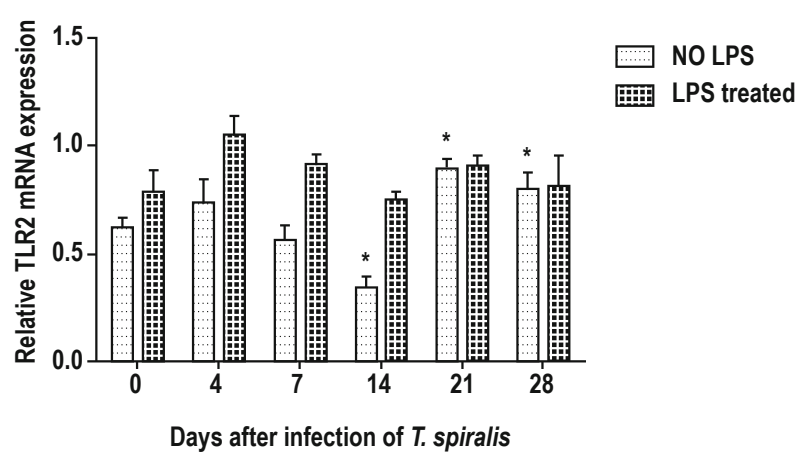

B

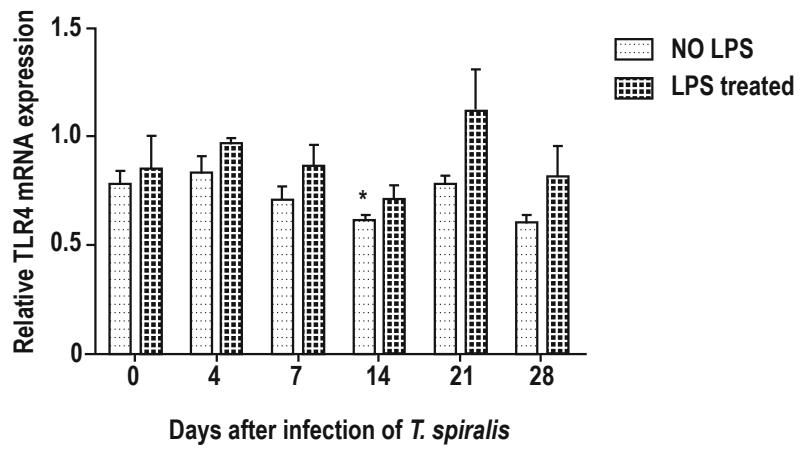

Fig. 3. The TLR2 (A) and TLR4 (B) mRNA expression in macrophages in mice after infection with T. spiralis at the indicated time points by RT-PCR. Cells were either left untreated with LPS for $12 \mathrm{~h}$ or treated for the same time with LPS (final conc., $100 \mathrm{ng} / \mathrm{ml}$ ) for $12 \mathrm{~h}$. A total RNA was purified from cells and TLR mRNA were assayed by semi-quantitative RT-PCR.

\section{Western blot analysis}

Macrophages were collected and proteins were extracted according to the manufacturer's handbook (KeyGEN BioTECH, Nanjing, China). Protein concentrations in each sample were determined by Bradford Protein Assay Kit (KeyGEN BioTECH, Nanjing, China). The proteins were then separated with $10 \%$ SDS-PAGE and transferred on nitrocellulose membrane, which was blocked overnight with $5 \%$ (w/v) non-fat dry milk in TBST $(20 \mathrm{mmol} / \mathrm{l}$ Tris-HCl (pH 7.6), $150 \mathrm{mmol} / \mathrm{l} \mathrm{NaCl}$ and $0.02 \%$ Tween 20). Membranes were then washed three times for $10 \mathrm{~min}$ in TBST and incubated for $1 \mathrm{hr}$ at $37^{\circ} \mathrm{C}$ with rabbit polyclonal anti-MyD88, anti-NF-KB and anti- $\beta$-actin primary antibodies (Bioss, Beijing, China). In addition, anti- $\beta$-actin was used to detect $\beta$-actin expression as a quantitative control. After being washed three times for $10 \mathrm{~min}$ in TBST the membranes were incubated for $1 \mathrm{hr}$ at RT with horseradish peroxidase (HRP)-conjugated secondary antibody. The membranes were then washed again three times in TBST and protein bands were visualized with the ECL enhanced chemiluminescent (HaiGene, Harbin).

\section{Statistical analysis}

Results are presented as mean \pm SD. Significance of the differences between experimental and control groups were calculated using Student's $t$ test. In all cases, a $p$ value less than 0.05 was considered to be statistically significant.

\section{Ethical Approval}

All animal husbandry and experimental procedures were performed in accordance with the Chinese Animal Management Ordinance (People's Republic of China Ministry of Health document No.55 in 2001). The research related to animals use has been complied with all the relevant national regulations and institutional policies for the care and use of animals.

\section{Results}

\section{Cytokine measurement}

The expression of TNF-a, IL-6, IL-10, IL-12 and NO in the LPS-stimulated macrophages from the infected mice was detected

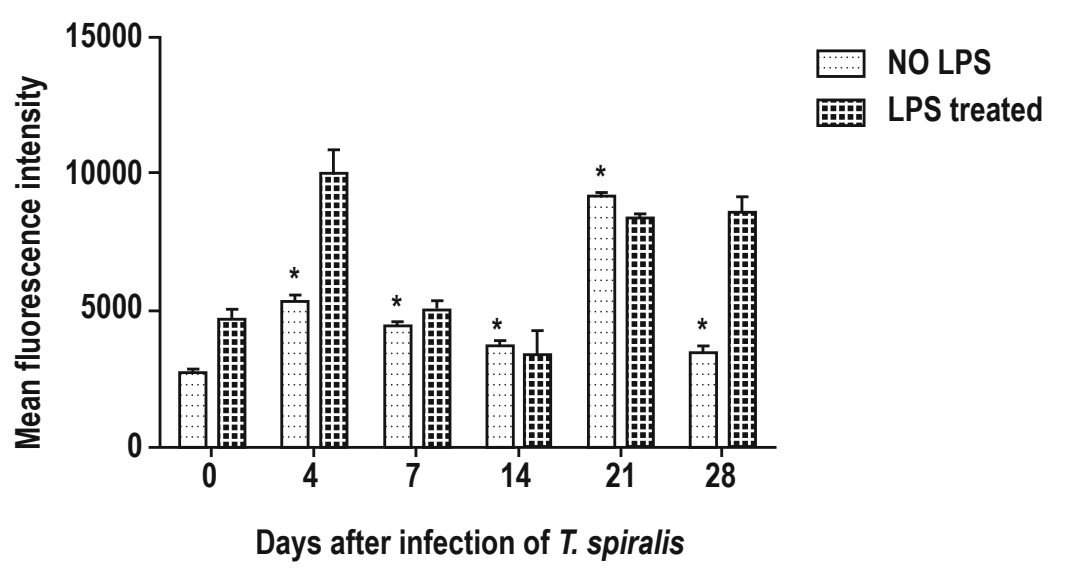

Fig. 4. The MFI of TLR4 in macrophages in mice after infection with T. spiralis at indicated time points by flow cytometry. Flow cytometry was carried out and analyzed on a FACScalibur (BD, ADD CITY, USA) with FACS Diva 6.0 software. 


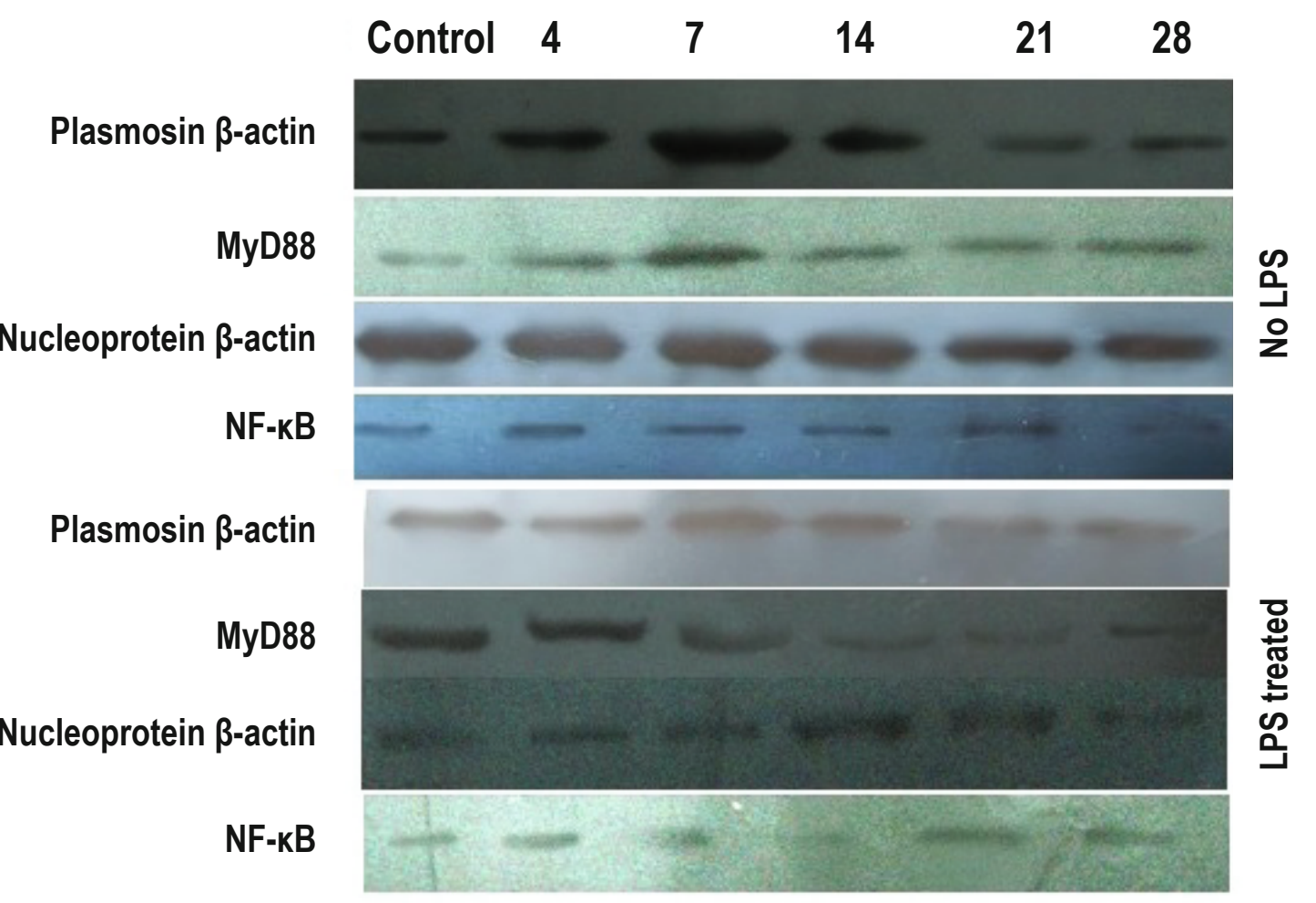

Fig. 5. MyD88 and NF-KB expression in macrophages after infection with $T$. spiralis at indicated time points by western blot. Cells were treated with LPS (final conc., 100 $\mathrm{ng} / \mathrm{ml}$ ) for $12 \mathrm{~h}$. The protein was detected in control group without $T$. spiralis infection. Protein samples were analyzed by western blot with phospho-specific antibodies. $4,7,14,21$ and 28: The time points (days) after the infection of $T$. spiralis.

by ELISA. TNF-a (Fig. $1 \mathrm{~A}$ ) levels were up-regulated in non-LPS treated macrophages at days 14 and 21 p. i.. Higher IL-6 (Fig. $1 \mathrm{~B})$ expression readings in cell culture supernatants that were detected at days $7-21$ p. i., while the IL-10 (Fig. 1 C) and IL-12 (Fig. $1 \mathrm{D}$ ) levels were up-regulated only at day 4 p. i.. There were no differences in the cytokine production between LPS-treated macrophages and control. Upon the LPS stimulation, there were differences in TNF-a, IL-6 and IL-10 but not in IL-12 and NO (Fig. $1 \mathrm{E})$ between the groups at days $14-21 \mathrm{p}$. i.. The amount of NO (Fig. 2 A) significantly increased in the serum after $T$. spiralis infection, meanwhile the levels of TNF-a (Fig. 2 B), IL-10 (Fig. 2 C) and IL-12 (Fig. 2 D) decreased significantly. However, no changes were detected in IL-6 expression (Fig. 2 E).

\section{Quantification of TLRs expression}

To determine whether the TLRs expression was differently regulated, the mRNA of TLRs was determined in macrophages of $T$. spiralis-infected mouse in vitro. The quantification of TLRs mRNA was measured by normalization to $\beta$-actin. The TLR2 expression in LPS-stimulated macrophages was up-regulated when compared with naive cells (Fig. $3 \mathrm{~A}$ ). There was no difference in the TLR2 expression between macrophages with or without LPS stimulation, except day 21 p. i. (Fig. 3 B). There was no difference in the TLR4 expression between the LPS-stimulated and non-LPS stimulated cells on day 14 p. i Flow cytometry showed that the TLR4 expression decreased only at day $21 \mathrm{p}$. i. in the LPS-stimulated macrophages when compared with naive cells (Fig. 4).

\section{Expression of MyD88 and NF-KB by Western blot analysis}

It is known that MyD88-dependent pathway is one of the TLRs signaling pathways mediated universally by all TLRs. The expression of MyD88 and NF-KB involved in activating or regulating TLRs signaling was examined on macrophages at indicated time points after $T$. spiralis infection. The MyD88 and NF-KB expressed on macrophages were similar to the TLR4 mRNA expression pattern (Fig. 5). The expression of MyD88 was up-regulated on day 4 and 7 p.i. at intestinal phase. So we inferred that the intestinal adult may activate the MyD88. In addition, the expression of MyD88 was up-regulated by the muscle larvae. Relative MyD88 and NF-KB expression in no LPS show statistical significance at day 21 and 28 p.i. (Fig. 6 A, B). Those days represent chronic infection. The exact mechanism needs further investigation.

\section{Discussion}

Helminthes parasites are of considerable medical and economic importance. Studies on the immune response against helminthes are of great interest by reason of understanding the interactions 
A

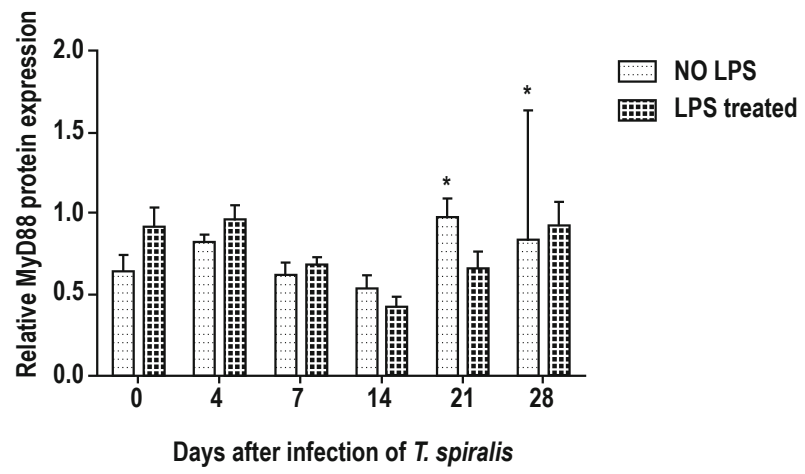

B

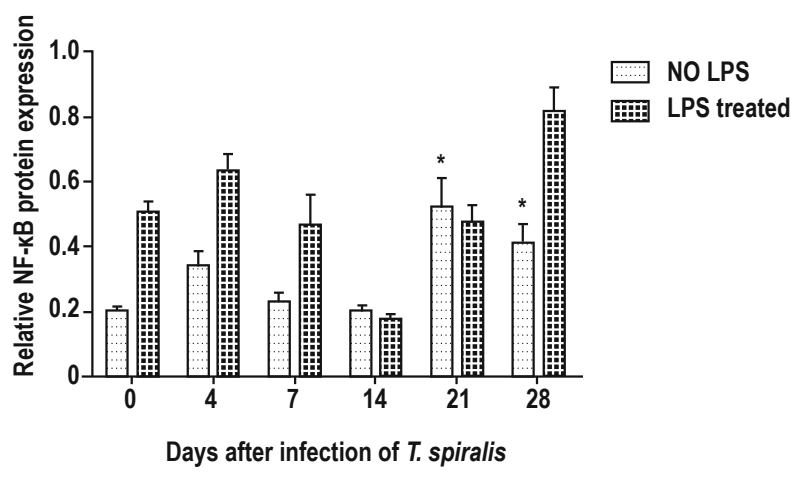

Fig. 6. The expression of MyD88 (A) and NF-KB (B) in macrophages after infection with $T$. spiralis at the indicated time points. Cells treated with or without LPS (final conc., $100 \mathrm{ng} / \mathrm{ml}$ ) for $12 \mathrm{~h}$. The protein concentrations were determined by using the Bradford Protein Assay Kit. Expression is normalized to $\beta$-actin.

between host immune system and parasites (Moreau et al., 2010). In order to maintain their life cycle, helminthes parasites can modulate the host's immune response that would enable their longterm survival within the host. Parasites are able to persist in the host and are mainly responsible for chronic infection despite a strong immune response developed by the parasitized host (llic et al., 2011). The pathogenic organisms (virus, bacteria and parasite) can activate antigen presentation cells (APCs) primarily through pattern recognition receptors - TLR recognition and signaling (Yu et al., 2013; Kim et al., 2015). The antigen component of $T$. spiralis may possibly serve as a ligand of TLR4 and ES antigen suppressed cytokine production and expression of co-stimulatory markers on DCs induced by TLR4. It was found that the expression of CD40, CD80 and CD86 of the DCs surface and cell factors (IL-6, IL-10 and TNF-a) was decreased (Langelaar et al., 2009). Previous study has demonstrated that macrophages play crucial roles in host immune responses against various pathogens (Bai et al., 2012). Given the recent advances in activated macrophages under the control of Th2-dependent cytokines expression in helminthes infection (Bruschi et al., 2008), the expression levels of TLR2 and TLR4 on macrophages in T. spiralis infection was investigated. Our results showed that the mRNA expression of macrophages TLRs in vivo was differently regulated throughout T. spiralis infection. The TLR2 expression was increased only in the LPS-stimulated macrophages but not in non- stimulated macrophages at day $4 \mathrm{p}$. i.. The expression levels of TLR2 and TLR4 decreased gradually from day $7 \mathrm{p}$. i. Probably due to increased antigens production induced by newborn Trichinella larvae what suggest that newborn larvae have extensive inhibitory effects on host immune response. The expression was lowest at day $14 \mathrm{p}$. i. and increased gradually up to day 21 thus contributing to the tolerance elimination and formation of the cysts in muscles. These results suggest that $T$. spiralis ES products at each stage of infection are potential factors for regulation of host immune response by modulation of TLRs expression and signal pathways in macrophages. Intestinal DCs and macrophages retain regulatory mechanisms what prevent excessive inflammation, and there is an active suppression of pro-inflammatory cytokine production by regulatory cytokine such as IL-10 (Pulendran et al., 2010; Beiting et al., 2007). Macrophages stimulated by LPS differentiate into classically activated macrophages and release a number of immune mediator molecules (IL-12, IL-6, TNF-a, nitric oxide - NO), which play critical roles in initiation and modulation of the host immune responses to parasite infections (Bai et al., 2012; Noel et al., 2004). Further we investigated the dynamic changes of cell factors from different stages of $T$. spiralis in serum and macrophages. TNF-a, IL-6, IL-10 and $\mathrm{IL}-12$ were decreased in LPS-stimulated macrophages, as well as TNF-a, IL-6, IL-10 and IL-12 in serum. Results are comparable with those of Bai and colleges who found that the ES products from different stages of $T$. spiralis infection significantly suppressed the production of pro-inflammatory TNF- $\alpha$, IL-I $\beta$, IL-6 and IL-12 in LPS-stimulated macrophages in vitro (Bai et al., 2012). NO was reported to play an important role in induction of intestinal physiology and inflammation during T. spiralis infection (Lawrence et al., 2000). The regulation of $\mathrm{NO}$ release is associated with iNOS release, and induced macrophages can produce the enzyme NOS2 (an enzyme responsible for the production of nitric oxide) which transforms L-arginine to nitric oxide, responsible for parasite damage (Bruschi et al., 2011). Our results showed that the NO expression was increased in serum and decreased in LPS-stimulated macrophages at day 21 p. i.. Our results are consistent with the findings that ES products had a suppressive effect on LPS-stimulated iNOS expression in macrophages (Bai et al., 2012).

The NF-kB signaling pathway regulates LPS-stimulated pro-inflammatory response in macrophages. The ES products of helminthes have been found to inhibit NF-kB activation (Puneet et al., 2011). Trichinella ES products are able to inhibit the LPS-stimulated nuclear translocation of p65 and also reduce ERK1/2 and p38 MAPK phosphorylation (Bai et al., 2012). TLR4 signaling involves two main intracellular pathways. One is MyD88-dependent pathway which mediates the production of pro-inflammatory cytokines and second is MyD88-independent or TRIF pathway which medi- 
ates the up-regulation of co-stimulatory and MHC II molecules on DCs (Du et al., 2014; Scalfone et al., 2013). Here we found that the expression levels of NF-KB and MyD88 was similar to the TLR4 expression in LPS-stimulated macrophages in vivo. The TLR4 expression changes induced by $T$. spiralis infection could activate the TLR4/MyD88/NF-KB signaling pathway and also effect the secretion of inflammatory cytokines in macrophages, what could participate in immune suppression.

In summary, we confirmed that experimental $T$. spiralis infection in mice could modulate the host immune response. Different stages of infection had different effects on cytokine profiles, as well as the TLRs and related signaling molecules in macrophages. The expression of TLR2 and TLR4 were modulated at different stages of $T$. spiralis infection. The cytokine levels were regulated through TLR4-mediated signaling pathway, suggesting that TLR4 modulated the immunosuppression of the host. This study provides fresh insights into the mechanisms of TLR-mediated post-inflammatory response during $T$. spiralis infection.

\section{Conflict of Interest}

Authors state no conflict of interest. Authors have no potential conflict of interest pertaining to this submission to Helminthologia.

\section{Acknowledgments}

Project support was provided by grants from the National Natural Science Fund (Project No. 31172312), the National Key Research and Development Program of China (2017YFD0501302) and Heilongjiang Key Laboratory for Zoonosis. Liping Meng is thanked for her constructive comments on the draft manuscript.

\section{References}

Aranzamendi, C., de Bruin, A., Kuiper, R., Boog, C.J., van Eden, W., Rutten, V., PInelli, E. (2013): Protection against allergic airway inflammation during the chronic and acute phases of Trichinella spiralis infection. Clin. Exp. Allergy, 43(1): 103 - 115. DOI: 10.1111/ cea. 12042

Aranzamendi, C., Fransen, F., Langelaar, M., Franssen, F., van der Ley, P., van Putten, J.P., Rutten, V., Pinelul, E. (2012): Trichinella spiralis-secreted products modulate DC functionality and expand regulatory T cells in vitro. Parasite Immunol., 34(4): 210 - 223. DOI: 10.1111/j.1365-3024.2012.01353.x

Bal, X., Wu, X., Wang, X., Guan, Z., Gao, F., Yu, J., Yu, L., Tang, B., Liu, X., Song, Y., Wang, X., Radu, B., Boireau, P., Wang, F., Liu, M. (2012): Regulation of cytokine expression in murine macrophages stimulated by excretory/secretory products from Trichinella spiralis in vitro. Mol. Cell. Biochem., 360(1 - 2): 79 - 88. DOI: 10.1007/ s11010-011-1046-4

Beiting, D.P., Gagliardo, L.F., Hesse, M., Bliss, S.K., Meskill, D., Appleton, J.A. (2007): Coordinated control of immunity to muscle stage Trichinella spiralis by IL-10, regulatory T cells, and TGF-beta. J. Immunol., 178(2): 1039 - 1047

Blum, L.K., Mohanan, S., Fabre, M.V., Yafawi, R.E., Appleton, J.A. (2013): Intestinal infection with Trichinella spiralis induces distinct, regional immune responses. Vet. Parasitol., 194(2 - 4): 101 - 105. DOI: 10.1016/j.vetpar.2013.01.030

Bruschi. F., Chiumiento, L. (2011): Trichinella inflammatory myopathy: host or parasite strategy? Parasit. Vectors, 4: 42. DOI: 10.1186/1756-3305-4-42

Bruschi, F., Korenaga, M., Watanabe, N. (2008): Eosinophils and Trichinella infection: toxic for the parasite and the host? Trends Parasitol., 24(10): 462 - 467. DOI: 10.1016/j.pt.2008.07.001

Chen, X., YAng, Y., YAng, J., Zhang, Z., ZHu, X. (2012): RNAi-mediated silencing of paramyosin expression in Trichinella spiralis results in impaired viability of the parasite. PLoS One, 7(11): e49913. DOI: 10.1371/journal.pone.0049913

Cul, J., Ren, H.J., Liu, R.D., Wang, L., Zhang, Z.F., Wang, Z.Q. (2013):Phage-displayed specific polypeptide antigens induce significant protective immunity against Trichinella spiralis infection in BALB/c mice. Vaccine, 31(8): 1171 - 1177. DOI: 10.1016/j.vaccine.2012.12.070

Du, L., LIU, L., Yu, Y., Shan, H., LI, L. (2014): Trichinella spiralis excretory-secretory products protect against polymicrobial sepsis by suppressing MyD88 via mannose receptor. Biomed. Res. Int., 2014: 898646. DOI: 10.1155/2014/898646

Gruden-Movsesijan, A., Ilic, N., Colic, M., Majstorovic, I., Vasilev, S., Radovic, I., Sofronic-MilosavlJeVIC, L. (2011): The impact of Trichinella spiralis excretory-secretory products on dendritic cells. Comp. Immunol. Microbiol. Infect. Dis., 34(5): 429 - 439. DOI: 10.1016/j.cimid.2011.08.004

Gruden-Movsesijan, A., Ilic, N., Mostarica-Stojkovic, M., Stosic-Grujicic, S., Milic, M., Sofronic-Milosavluevic, L. (2010): Mechanisms of modulation of experimental autoimmune encephalomyelitis by chronic Trichinella spiralis infection in Dark Agouti rats. Parasite Immunol., 32(6): 450 - 459. DOI: 10.1111/j.13653024.2010.01207.x

ilic, N., Gruden-Movsesijan, A., Sofronic-Milosavluevic, L. (2012): Trichinella spiralis: shaping the immune response. Immunol. Res., 52(1 - 2): 111 - 119. DOI: 10.1007/s12026-012-8287-5

llic, N., Worthington, J.J., Gruden-Movsesijan, A., Travis, M.A., Sofronic-Milosavluevic, L., Grencis, R.K. (2011): Trichinella spiralis antigens prime mixed Th1/Th2 response but do not induce de novo generation of Foxp3+ T cells in vitro. Parasite Immunol., 33(10): 572 - 582. DOI: 10.1111/j.1365-3024.2011.01322.x

Kang, S.A., Cho, M.K., Park, M.K., Kim, D.H., Hong, Y.C., Lee, Y.S., CHA, H.J., Ock, M.S., Yu, H.S. (2012): Alteration of helper T-cell related cytokine production in splenocytes during Trichinella spiralis infection. Vet. Parasitol., 186(3 - 4): 319 - 327. DOI: 10.1016/j. vetpar.2011.12.002

KIM, S., PARK, M.K., Yu, H.S. (2015): Toll-Like Receptor Gene Expression during Trichinella spiralis Infection. Korean J. Parasitol., 53(4): 431 - 438. DOI: 10.3347/kjp.2015.53.4.431 
Langelaar, M., Aranzamendi, C., Franssen, F., Van Der Giessen, J., Rutten, V., van der Ley, P., Pinelli, E. (2009): Suppression of dendritic cell maturation by Trichinella spiralis excretory/ secretory products. Parasite Immunol., 31(10): 641 - 645. DOI: 10.1111/j.1365-3024.2009.01136.x

Lawrence, C.E., Paterson, J.C., Wei, X.Q., Liew, F.Y., Garside, P., KenNEDY, M.W. (2000): Nitric oxide mediates intestinal pathology but not immune expulsion during Trichinella spiralis infection in mice. J. Immunol., 164(8): 4229 - 4234

Lı, X., Liu, W., Wang, J., Zou, D., Wang, X., Yang, Z., Yin, Z., Cui, Q., Shang, W., Lı, H., Wei, X., Cuı, J., Wang, Z., Huang, L., Yuan, J. (2012): Rapid detection of Trichinella spiralis larvae in muscles by loop-mediated isothermal amplification. Int. J. Parasitol., 42(13 14): 1119 - 1126. DOI: 10.1016/j.jpara.2012.09.011

Liu, A.Y., Dwyer, D.F., Jones, T.G., Bankova, L.G., Shen, S., Katz, H.R., Austen, K.F., GuRISH, M.F. (2013): Mast cells recruited to mesenteric lymph nodes during helminth infection remain hypogranular and produce IL-4 and IL-6. J. Immunol., 190(4): 1758 - 1766. DOI: 10.4049/jimmunol.1202567

Mido, S., Fath, E.M., Farid, A.S., Nonaka, N., Oku, Y., HorII, Y. (2012): Trichinella spiralis: infection changes serum paraoxonase-1 levels, lipid profile, and oxidative status in rats. Exp. Parasitol., 131(2): 190 - 194. DOI: 10.1016/j.exppara.2012.03.023

Moreau, E., Chauvin, A. (2010): Immunity against helminths: interactions with the host and the intercurrent infections. J. Biomed. Biotechnol., 2010: 428593. DOI: 10.1155/2010/428593

Motran, C.C., Ambrosio, L.F., Volpini, X., Celias, D.P., Cervi, L. (2017): Dendritic cells and parasites: from recognition and activation to immune response instruction. Semin. Immunopathol., 39(2): 199 - 213. DOI: 10.1007/s00281-016-0588-7

Noel, W., Raes, G., Hassanzadeh Ghassabeh, G., De Baetselier, P., BeschIN, A. (2004): Alternatively activated macrophages during parasite infections. Trends Parasitol., 20(3): 126 - 133. DOI: 10.1016/j.pt.2004.01.004

Pulendran, B., Tang, H., Manicassamy, S. (2010): Programming dendritic cells to induce $\mathrm{T}(\mathrm{H}) 2$ and tolerogenic responses. Nat. Immunol., 11(8): 647 - 655. DOI: 10.1038/ni.1894
Puneet, P., McGrath, M.A., Tay, H.K., Al-Riyami, L., Rzepecka, J., Moochhala, S.M., Pervalz, S., Harnett, M.M., Harnett, W., MeLENDEZ, A.J. (2011): The helminth product ES-62 protects against septic shock via Toll-like receptor 4-dependent autophagosomal degradation of the adaptor MyD88. Nat. Immunol., 12(4): 344 351. DOI: $10.1038 /$ ni.2004

Radovic, I., Gruden-Movsesijan, A., Ilic, N., Cvetkovic, J., Mojsilovic, S., Devic, M., Sofronic-Milosavljevic, L. (2015): Immunomodulatory effects of Trichinella spiralis-derived excretory-secretory antigens. Immunol. Res., 61(3): 312 - 325. DOI: 10.1007/ s12026-015-8626-4

Riva, E., Steffan, P., Guzman, M., Fiel, C. (2012): Persistence of Trichinella spiralis muscle larvae in natural decaying mice. Parasitol. Res., 111(1): 249 - 255. DOI: 10.1007/s00436-012-2826-9

Scalfone, L.K., Nel, H.J., Gagliardo, L.F., Cameron, J.L., Al-Shokri, S., Leifer, C.A., Fallon, P.G., Appleton, J.A. (2013): Participation of MyD88 and interleukin-33 as innate drivers of Th2 immunity to Trichinella spiralis. Infect. Immun., 81(4): 1354 - 1363. DOI: 10.1128/IAI.01307-12

Thrasher, S.M., Scalfone, L.K., Holowka, D., Appleton, J.A. (2013): In vitro modelling of rat mucosal mast cell function in Trichinella spiralis infection. Parasite Immunol., 35(1): 21 - 31.10.1111/ pim.12014

Yadav, A.K., Temuenmongla (2012): Efficacy of Lasia spinosa leaf extract in treating mice infected with Trichinella spiralis. Parasitol. Res., 110(1): 493 - 498. DOI: 10.1007/s00436-011-2551-9

Yang, J., Gu, Y., Yang, Y., Wel, J., Wang, S., Cul, S., Pan, J., LI, Q., ZHU, X. (2010): Trichinella spiralis: immune response and protective immunity elicited by recombinant paramyosin formulated with different adjuvants. Exp. Parasitol., 124(4): 403 - 408. DOI: 10.1016/j.exppara.2009.12.010

Yu, Y.R., Deng, M.J., Lu, W.W., JIA, M.Z., Wu, W., Qı, Y.F. (2013): Systemic cytokine profiles and splenic toll-like receptor expression during Trichinella spiralis infection. Exp. Parasitol., 134(1): 92 101. DOI: 10.1016/j.exppara.2013.02.014 